\title{
Snipings
}

The rubric 'Snipings', introduced into the World Trade Review in 2004, is intended for contributions which, while rigorous, are shorter and therefore less extensively developed and documented than our standard length articles. It offers, among other things, an opportunity for early analyses targeting topical policy issues concerning the multilateral trading system. Submissions - which should be in the 1,500 to 4,500 word range - will be reviewed by independent referees.

This issue's Sniping is a little different, however, since it refers to a data source rather than analysis per se. As we witness the worst downturn for a generation, readers and researchers will be particularly interested in monitoring the introduction of policies that affect international trade. Thus the following brief note describes an important new source of data and analysis on recent policy changes.

\section{Global Trade Alert: Motivation and Launch}

\author{
SIMON J. EVENETT* \\ University of St. Gallen and CEPR
}

Unsurprisingly governments want to intervene during the current downturn, the challenge is to ensure that the measures taken are consistent with pledges to avoid protectionism. It should be recalled that G20 leaders vowed at the April 2009 London summit: 'We will not repeat the historic mistakes of protectionism of previous eras.' This pledge reiterated an earlier commitment made at the November 2008 G20 Summit in Washington, DC. Other heads of government have made similar pledges in regional fora, such as APEC and elsewhere.

To increase the information available on state measures that may affect trading partners' commercial interests, the Centre for Economic Policy Research (CEPR) has teamed up with independent research institutes from around the world to create Global Trade Alert (GTA). ${ }^{1}$ A combination of peer pressure plus up-to-date, comprehensive information, the latter being supplied by GTA, will help to maintain confidence in the world trading system, deter beggar-thy-neighbour acts, and

\footnotetext{
* Email: simon.evenett@unisg.ch

1 The network that makes up the Global Trade Alert, an initiative of the CEPR, is convened by Simon Evenett, co-director of the CEPR's International Trade and Regional Economics Programme.
} 
preserve the contribution that exports could play in the future recovery of the world economy. GTA seeks to inform debate and will not engage in naming-andshaming; others can judge.

Even though the world has not seen a return to the across-the-board tariff increases of the early 1930s, today's governments have resorted to massive stimulus packages, bailouts, and subsidies, many of which include nationalistic provisions that effectively harm trading partners' exporters, investors, and workers. The most recent WTO General Council meeting (in May 2009) confirmed that tensions between nations are growing, fuelled in part by the murky nature of current policies and the near absence of objective information upon which to assess policy. Moreover, calls were made at that meeting for more analysis of state measures taken during the recent global economic downturn. Since solid analysis builds on accurate information, GTA can make another contribution here.

Using a network of independent research institutes and trade experts from all over the globe, GTA will seek to identify those state measures that discriminate against foreign commercial interests, the latter broadly conceived to include imports, exports, foreign investments (including intellectual property), and foreign employees. GTA will not confine itself to the measures that are covered by the existing body of WTO agreements, it being understood that some prominent state measures taken during this crisis fall outside WTO agreements. Nor will the initiative pronounce on the WTO-legality of a measure or whether a measure is 'protectionist'.

Instead, where discrimination against foreign commercial interests can be documented (verification being an important part of any investigation into a state measure), the measure will be posted on the GTA website with a neutral explanation. Since the documentation of discrimination ideally rests on published state regulations or other acts, more posts on de jure discrimination than de facto discrimination are likely. Discriminatory measures that have been announced - but not implemented - will be investigated and potentially reported too.

Over the next twelve months, GTA will offer up-to-date, comprehensive, and impartial information on state measures on a dedicated website, www.globaltradealert.org. This website went live on 8 June 2009 and listed seven measures that are representative of the GTA's comprehensive scope. (Many more measures have been added since the launch.) Users will see that the initiative has not investigated solely the more transparent government measures. Moreover, available data have been used to identify trading partners likely to be affected by a state measure, an advance over other monitoring initiatives.

The GTA website has been deliberately designed so that users can sort the evergrowing database of reported measures by implementing jurisdiction, trading partners affected, and sector. This feature will make it easy for governments, industry, export associations, researchers, and others (including the media) to monitor developments that affect them. Users can sign up for email notifications about newly posted measures, and can report measures which the GTA team will 
investigate. These features of the GTA website will add to the openness and transparency of the world trading system.

In addition to being able to track government measures taken during the current global economic downturn, the stock of measures that are reported on the GTA website will grow and so provide researchers and government officials with information on any new patterns of state intervention that are problematic from the perspective of maintaining open borders. As those familiar with the sharp downturn in the early 1980s and the launch of the Uruguay Round in 1986 will appreciate, the information collected during monitoring exercises such as these can subsequently influence commercial policy priorities of nations.

Information about the participants, sponsors, and methods used in GTA can be found on the website. ${ }^{2}$ Given the advances in web-based technology, taking monitoring 'on line' was surely inevitable. An important public policy question for later is whether such on-line monitoring of state measures should become a permanent feature of the worldwide trade policy landscape and, if so, on what terms.

Any suggestions that you may have about improving GTA are most welcome and will be shared with the initiative's participants. To date meetings in London and Geneva have provided important suggestions for substance, process, and presentation and these are being followed up. During the implementation of an initiative such as this, it is inevitable that a fair amount of learning takes place. Much of that learning will follow from extensive listening, hence the GTA's multiple launches and outreach activities.

2 A wide range of funders were sought for this initiative, precisely to limit the actual or perceived influence of any one funder. The funders include: the UK Government, the Canadian International Development Research Centre, the Canadian Centre for International Governance Innovation, the German Marshall Fund of the United States, and the World Bank. 